\title{
Life-Threatening Mediastinal Teratoma of Infant Requiring Emergency Surgical Removal
}

\author{
Nicole Piber ${ }^{1}$ Wilko Weichert ${ }^{2}$ Jürgen Hörer ${ }^{1}$ Masamichi Ono ${ }^{1}$ \\ ${ }^{1}$ Deutsches Herzzentrum München des Freistaates Bayern, Munchen, \\ Bayern, Germany \\ ${ }^{2}$ Technical University of Munich Institute of Pathology and \\ Pathological Anatomy, Munchen, Bayern, Germany \\ Address for correspondence Masamichi Ono, MD, PhD, Department \\ for Congenital and Pediatric Heart Surgery, German Heart Center \\ Munich, Lazarettstr.36, 80636 Munich, Germany \\ (e-mail: Ono@dhm.mhn.de).
}

Thorac Cardiovasc Surg Rep 2022;11:e7-e10.

\begin{abstract}
Keywords

- mediastinal tumor

- teratoma

- infant

Background Teratoma is a tumor derived from fetal germ cells with aberrant differentiation.

Case Description A 3-month-old infant with a mediastinal tumor was referred to our heart center. She presented with progressive dyspnea, cyanosis, and the need to be manually ventilated. The computed tomography scan displayed a huge tumor restricting the distal trachea including the bifurcation. An emergent operation was performed and the tumor was completely removed. Histological examination confirmed a mature teratoma.

Conclusion In such life-threatening situation, the early detection and the immediate operation are very important for the management of rapidly-progressing mediastinal teratomas compressing the respiratory tract.
\end{abstract}

\section{Introduction}

Teratoma is a tumor derived from fetal germ cells with aberrant differentiation. Following the common pathway of migration gonadal teratomas may be caused, whereas an abnormal migration might lead to extragonadal tumors. ${ }^{1,2}$ Roughly, $5.4 \%$ of teratoma are found in the mediastinum mostly located in the anterior-superior area with a mortality of $18 \%^{2,3}$ Mediastinal teratoma presenting in the neonatal or early infantile age is uncommon. ${ }^{4}$ They frequently present with severe respiratory distress requiring urgent surgery. We describe the case of an early infant with a mediastinal teratoma who presented with progressive dyspnea, cyanosis, and low oxygen saturation due to the airway compression, and needed emergent surgical removal of the tumor via a median sternotomy.

\section{Case Description}

A 3-month-old female infant was referred to our heart center under the diagnosis of a mediastinal tumor for emergent surgical extirpation, eventually with the support of cardiopulmonary bypass or extracorporeal membrane oxygenation (ECMO). By admission, she presented with progressive dyspnea, cyanosis, and needed to be manually ventilated. The computed tomography (CT) scan displayed a tumor restricting the distal trachea including the bifurcation (-Fig. 1A). The ultra-sonogram showed hypo- and hyperdense areas and the size of $13 \times 9 \times 4 \mathrm{~cm}$ with no infiltration in the pericardial tissue. Due to the life-threatening situation, the infant was transferred immediately from intensive care unit to the operation room. Surgeons were ready for emergency thoracotomy. Once unproblematic intubation was achieved, received

January 10, 2021

accepted

January 28, 2021
DOI https://doi.org/

10.1055/s-0041-1726350.

ISSN 2194-7635. (c) 2022. The Author(s).

This is an open access article published by Thieme under the terms of the Creative Commons Attribution-NonDerivative-NonCommercial-License, permitting copying and reproduction so long as the original work is given appropriate credit. Contents may not be used for commercial purposes, or adapted, remixed, transformed or built upon. (https://creativecommons.org/ licenses/by-nc-nd/4.0/)

Georg Thieme Verlag KG, Rüdigerstraße 14, 70469 Stuttgart, Germany 

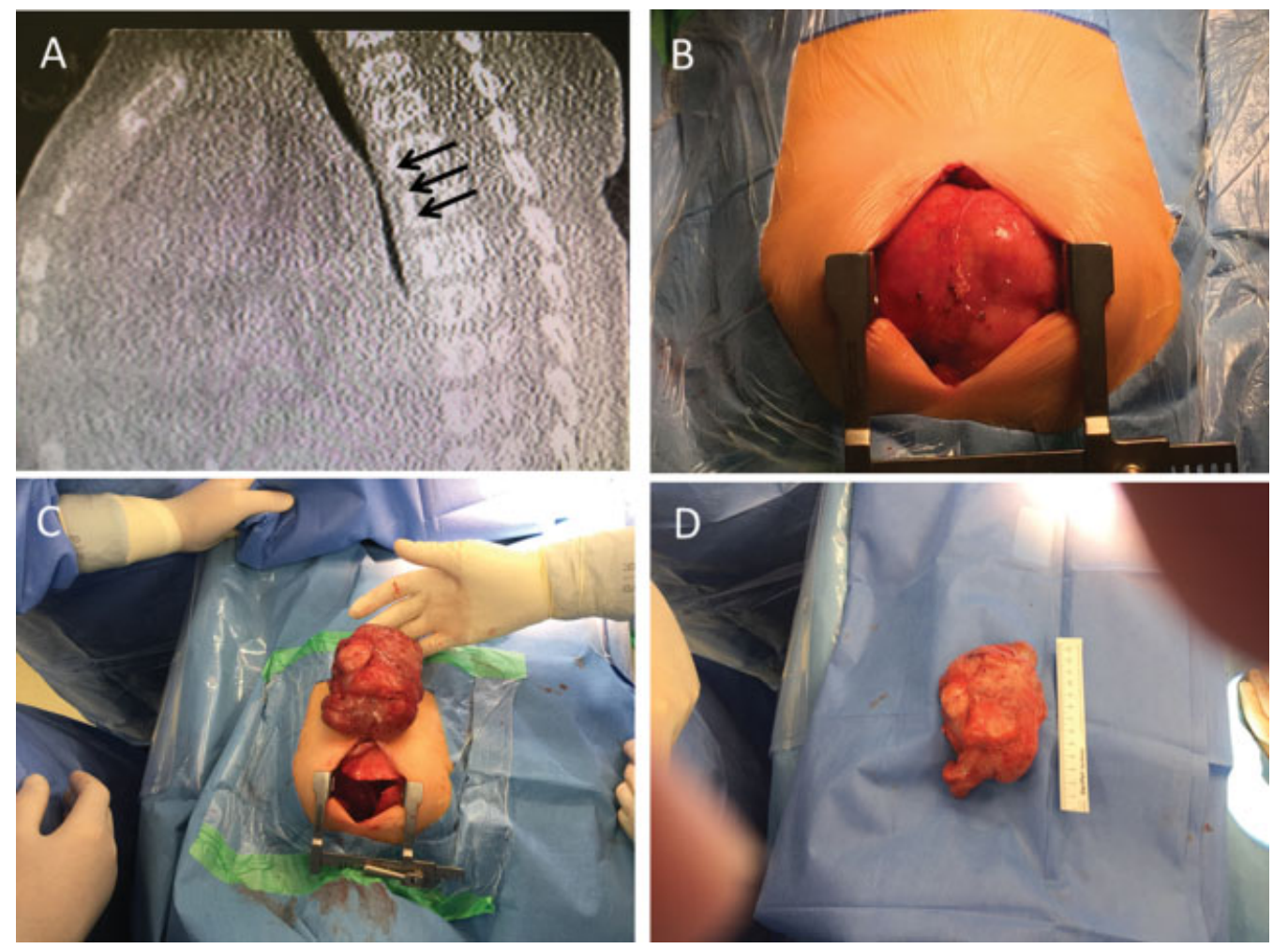

Fig. 1 Preoperative and operative findings. (A) Preoperative computed tomography demonstrated a huge mediastinal tumor compressing the distal trachea (black Arrow). (B) After a median sternotomy, a large mass occupying the thorax was exposed. (C) The tumor was carefully dissected en bloc. (D) The resected tumor demonstrated cystic and solid areas with measurement of $12 \times 7 \mathrm{~cm}$.

median sternotomy was performed in usual fashion. The mass exposed itself directly substernal and extended from the thymic gland between pleural and pericardial tissue in both thoracic cavities ( - Fig. 1B). Vascularization of the tumor was provided from a vessel deriving from the aortic arch and back to the innominate vein. No invasion of the tumor to the thoracic organs could be found. The tumor was carefully dissected en bloc ( - Fig. 1C and 1D). A misty effusion stood out in the left pleura that had to be drained. The postoperative recovery proceeded uneventfully. She was extubated on the first postoperative day and returned to the peripheral clinic on the second day postsurgery. At 15 months of follow-up, the patient was in good condition and showed no sign of recurrence.

\section{Histopathological Evaluation}

The resected tumor measured $11.2 \times 7.0 \times 4.6 \mathrm{~cm}$. The cut surface appeared brownish-yellow and featured mainly solid areas containing several cystic spaces ( - Fig. 2A). By histology, a multitude of different differentiated tissue types were apparent. The arrangement appeared in a haphazardous fashion. Mature cartilage ( - Fig. 2B), bone, fat, and muscle tissue were seen intermixed with brain parenchyma (-Fig. 2C), cutaneous adnexal structures as well as cysts lined by squamous and intestinal type epithelium containing goblet cells ( - Fig. 2D). Primitive neuroectodermal tubules were not present. This finally led to the diagnosis of a mature teratoma (G0 according to Gonzalez-Crussi) featuring tissue from all three germinal layers.

\section{Discussion}

Previous literatures described that germ cell tumors are present in one of 12,500 children under 15 years of age. ${ }^{5}$ About 10 to $15 \%$ of premediastinal tumors in children turn out to be mediastinal teratomas that most likely arise from cells adjacent to the third and fourth brachial clefts. ${ }^{6}$ Because of the rare location, the tumor is often misdiagnosed. ${ }^{7}$ Mori et al described CT criteria on how to distinguish between teratoma and thymoma, a common misdiagnosis in terms of mediastinal tumors. ${ }^{8}$ They demonstrated that teratomas are found to have a thicker wall and calcifications in a scattered lobular shape, whereas thymomas are lobulated and with no detectable wall between the surrounding structures. Calcification reminded of an eggshell.

The presentation of mediastinal teratomas in neonates and early infants is uncommon, and is sparsely documented. ${ }^{4,9-12}$ Mediastinal teratomas presenting in the neonatal or early infantile period cause various degree of respiratory distress. ${ }^{4}$ Therefore, urgent surgery is usually required. In severe cases, ECMO support is necessary to profound respiratory distress. ${ }^{13-15}$ In the presenting case, the infant presented with severe respiratory distress because the tumor compressed the trachea. Emergent surgery immediately after the submission was performed under the 

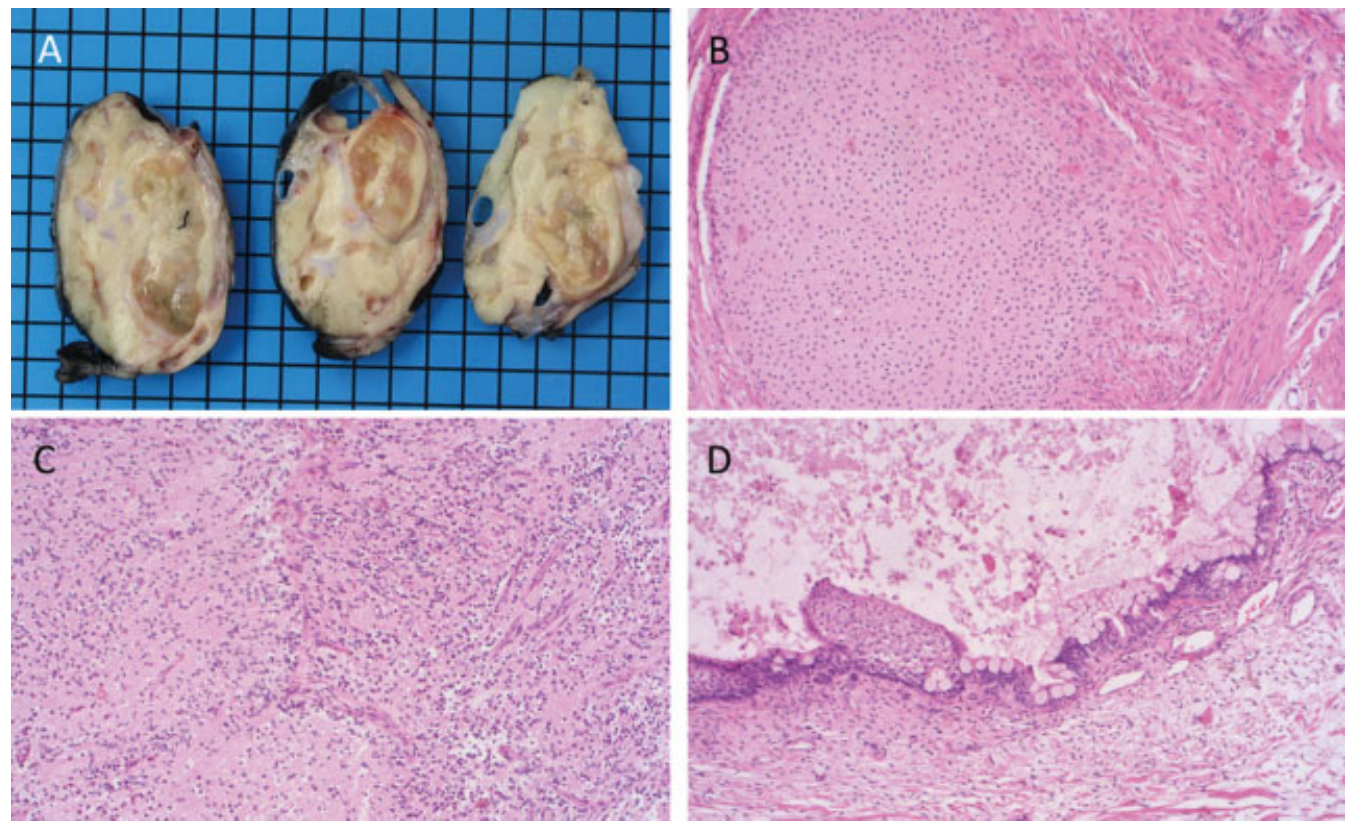

Fig. 2 Histologic findings: mature teratoma of a newborn. (A) Cross-sections through the tumor with cystic and solid areas. The teratoma featured a multitude of haphazardly arranged differentiated tissue elements such as cartilage (B), cysts lined with squamous as well as cylindrical intestinal type epithelium containing brain parenchyma (C), and goblet cells (D).

stand-by situation for cardiopulmonary bypass and ECMO. Fortunately, intubation and ventilation were successfully performed without circulatory collapse and there was no need for cardiopulmonary support.

Complete surgical excision is essential for the treatment of mediastinal teratomas, and median sternotomy is the standard procedure especially for small patients, allowing good exposure and approachability of the tumor. ${ }^{4}$ In the presenting case, no invasion of the tumor to the thoracic organs could be found, and the tumor was completely dissected. Histological examination confirmed the diagnosis of mature teratoma, and the patient showed no sign of recurrence at the last follow-up. The histological diagnosis and grading of tumor are crucial for planning the patients further management, and long-term follow-up is necessary for all patients to review the behavior of mediastinal teratoma.

In conclusion, we resected a huge mature mediastinal teratoma, which occupied the entire mediastinum and compressed the distal trachea including bifurcation in a 3month-old female infant. In the life-threatening situation, surgical removal of the tumor was performed by pediatric cardiothoracic surgeons under the "stand-by" of cardiopulmonary bypass support which is thought to be inevitable for the successful perioperative management of the very ill infant.

\section{Funding}

This study was not funded by any grant.

\section{Conflict of Interest}

There is no conflict exists. Author Nicole Piber declares that she has no conflict of interest. Author Wilko Weichert declares that he has no conflict of interest. Author Jürgen
Hörer declares that he has no conflict of interest. Author Masamichi Ono declares that he has no conflict of interest.

\section{References}

1 Oosterhuis JW, Stoop H, Honecker F, Looijenga LH. Why human extragonadal germ cell tumours occur in the midline of the body: old concepts, new perspectives. Int J Androl 2007;30(04):256-263 , discussion 263-264

2 Tapper D, Lack EE. Teratomas in infancy and childhood. A 54-year experience at the Children's Hospital Medical Center. Ann Surg 1983;198(03):398-410

3 Harms D, Zahn S, Göbel U, Schneider DT. Pathology and molecular biology of teratomas in childhood and adolescence. Klin Padiatr 2006;218(06):296-302

4 Lakhoo K, Boyle M, Drake DP. Mediastinal teratomas: review of 15 pediatric cases. J Pediatr Surg 1993;28(09):1161-1164

5 Kaatsch P, Kaletsch U, Michaelis J. Annual Report of the German Childhood Cancer Registry. www.kinderkrebsregister.de2018

6 Takeda S, Miyoshi S, Ohta M, Minami M, Masaoka A, Matsuda H. Primary germ cell tumors in the mediastinum: a 50-year experience at a single Japanese institution. Cancer 2003;97(02): 367-376

7 Tian Z, Liu H, Li S, et al. Surgical treatment of benign mediastinal teratoma: summary of experience of 108 cases. J Cardiothorac Surg 2020;15(01):36

8 Mori K, Eguchi K, Moriyama H, Miyazawa N, Kodama T. Computed tomography of anterior mediastinal tumors. Differentiation between thymoma and germ cell tumor. Acta Radiol 1987;28(04): 395-398

9 Bekker A, Goussard P, Gie R, Andronikou S. Congenital anterior mediastinal teratoma causing severe airway compression in a neonate. BMJ Case Rep 2013;2013:bcr2013201205

10 Stajevic M, Dizdarevic I, Krunic I, Topic V. Mediastinal teratoma presenting with respiratory distress and cardiogenic shock in a neonate. Interact Cardiovasc Thorac Surg 2020;30(05):788-789

11 Tovar JA. Anterior mediastinal tumors. Parikh DH, Crabbe DCG, Auldist AW, Sothenberg SS, eds. Pediatric Thoracic Surgery. London: Springer-Verlag; 2009:225-233 
e10 Life-Threatening Mediastinal Teratoma of Infant Requiring Emergency Surgical Removal Piber et al.

12 Zaidan H, Nguyen T, Corbally M, Dip G. Neonatal mediastinal teratoma: a cause of neonatal respiratory distress. Bahrain Med Bull 2015;37:204-206

13 Seo $\mathrm{T}$, Ando $\mathrm{H}$, Watanabe $\mathrm{Y}$, et al. Acute respiratory failure associated with intrathoracic masses in neonates. J Pediatr Surg 1999;34(11):1633-1637

14 Kelly MF, Berenholz L, Rizzo KA, Greco R, Wolfson P, Zwillenberg DA. Approach for oxygenation of the newborn with airway obstruction due to a cervical mass. Ann Otol Rhinol Laryngol 1990;99(3 Pt 1):179-182

15 Brenn BR, Reddy SK, Van Arendonk KJ, Morgan WM. Perioperative management of an anterior mediastinal teratoma in an infant: one more tool in the toolbox. BMJ Case Rep 2018; $\cdots$ : bcr2018227022 